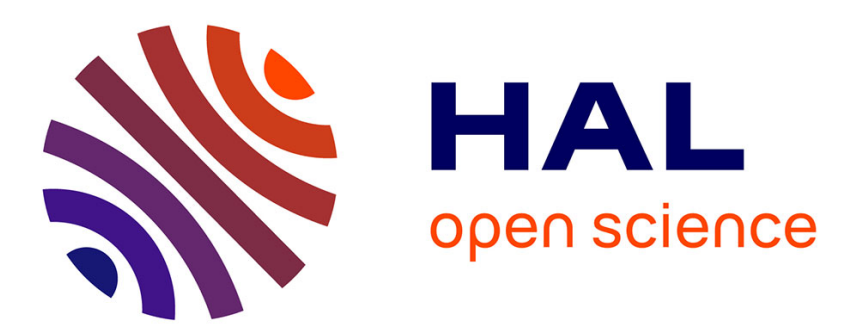

\title{
Influence of plasma diffusion losses on dust charge relaxation in discharge afterglow
}

\author{
Lénaïc Couëdel, Alexander A. Samarian, Maxime Mikikian, Laifa Boufendi
}

\section{To cite this version:}

Lénaïc Couëdel, Alexander A. Samarian, Maxime Mikikian, Laifa Boufendi. Influence of plasma diffusion losses on dust charge relaxation in discharge afterglow. Fifth International Conference on the Physics of Dusty Plasmas, May 2008, Ponta Delgada, Azores, Portugal. pp.183, 10.1063/1.2996828 . hal-00327719

\section{HAL Id: hal-00327719 \\ https://hal.science/hal-00327719}

Submitted on 9 Oct 2008

HAL is a multi-disciplinary open access archive for the deposit and dissemination of scientific research documents, whether they are published or not. The documents may come from teaching and research institutions in France or abroad, or from public or private research centers.
L'archive ouverte pluridisciplinaire HAL, est destinée au dépôt et à la diffusion de documents scientifiques de niveau recherche, publiés ou non, émanant des établissements d'enseignement et de recherche français ou étrangers, des laboratoires publics ou privés. 


\title{
Influence of plasma diffusion losses on dust charge relaxation in discharge afterglow
}

\author{
L. Couëdel*,†, A.A. Samarian*, M. Mikikian ${ }^{\dagger}$ and L. Boufendi ${ }^{\dagger}$ \\ ${ }^{*}$ School of Physics, The University of Sydney, NSW 2006 ,Australia \\ ${ }_{\dagger}^{\dagger}$ GREMI, CNRS/Université d'Orléans, 14 rue d'Issoudun, BP6744, 45067 Orleans Cedex 2, \\ France
}

\begin{abstract}
The influence of diffusive losses on residual dust charge in a complex plasma afterglow has been investigated. The dust residual charges were simulated based on a model developed to describe complex plasma decay. The experimental and simulated data show that the transition from ambipolar to free diffusion in the decaying plasma plays a significant role in determining the residual dust particle charges. The presence of positively charged dust particles is explained by a broadening of the charge distribution function in the afterglow plasma.
\end{abstract}

Keywords: Dust particles, afterglow, complex plasma

PACS: 52.27.Lw

Dust particle charge is a key parameter in a complex plasma. It determines the interaction between a dust particle and electrons, ions, its neighboring dust particles, and electric field [1]. Data of the dust charge will allow us to understand the particle dynamics in dust clouds, and methods of manipulating the particles. The knowledge of the dust charge is very important in every dusty medium (complex plasmas, colloidal suspensions, fog). There are many publications reporting on the investigation of dust charging in a discharge plasma. However there are only a few papers devoted to dust charging, or decharging to be more specific, in the afterglow plasma.

It has been shown that, when a discharge is turned off, dust particles keep small residual charges in the late afterglow [2]. Moreover, the mean dust particle residual charge is negative but some particles are neutral and others are positively charged. Dust residual charge distribution measurement shows that the distribution is wider than the one predicted for a running discharge [1]. However, no theoretical explanations of this phenomenon are available to date. The models proposed do not predict accurately residual charge values observed in those experiments, nor do they explain the existence of positively charged particles. One of the main reasons is that the models are working with simple assumptions. For this reason, a model taking into account the actual transition from ambipolar to free diffusion $[3,4]$ of electrons and ions is vital for the correct calculation of dust charges in afterglow plasma.

Here we report numerical simulation on dust particle charge relaxation in an afterglow plasma for various transitions from ambipolar to free diffusion. The ion and electron density decay were calculated using fluid equations. The dust particle charge distributions were calculated using a Focker-Planck model of dust charging process based on the OML model [5].

As it can be seen in Fig.1, the first decrease of the dust particle charge corresponds to the 

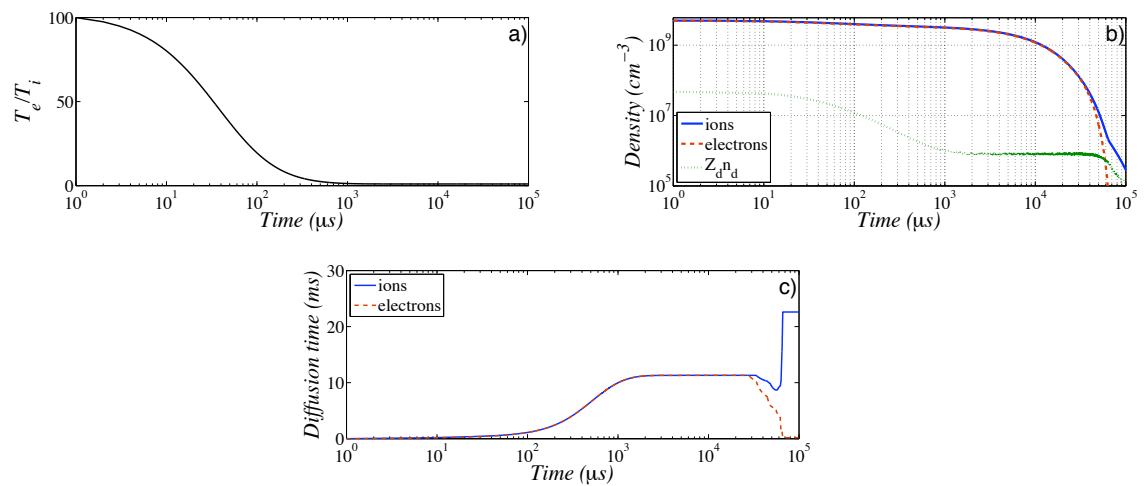

FIGURE 1. (Color Online) Decay of an argon plasma at $P=1.2 \mathrm{mbar}$ with a fast ambipolar-to-free diffusion transition. a) Electron temperature relaxation; b)density evolution; c) evolution of diffusion time.

electron temperature relaxation. Then, while electrons and ions diffuse ambipolarly, the charge remains constant. Finally, when the transition occurs (after tens of ms), electron and ions densities deviate from each other and the dust charge deacreases until it freezes. The importance of the transition from ambipolar to free diffusion in the decaying plasma for determining the dust particle residual charges is shown (Fig.2). The broadening of the charge distribution function is found to be responsible for the presence of positively charged particles. A fast transition from ambipolar to free diffusion leads to a negative mean residual charge of few electrons and a very wide dust charge distribution that extends in the positive region (Fig.2(d)) while a slow transition leads to highly negative mean residual charge and no positively charged dust particles (Fig.2(c)).
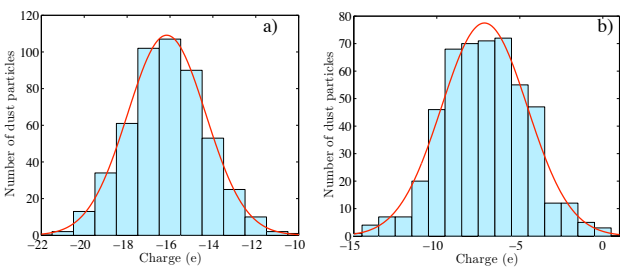

FIGURE 2. (Color Online) Numerical results for $190 \mathrm{~nm}$ radius dust particles with argon pressure $P=$ $1.2 \operatorname{mbar}(P=0.9$ Torr $)$ and $n_{d}=5 \cdot 10^{4} \mathrm{~cm}^{-3}$.a) Ambipolar diffusion until the end of the decay process. b)
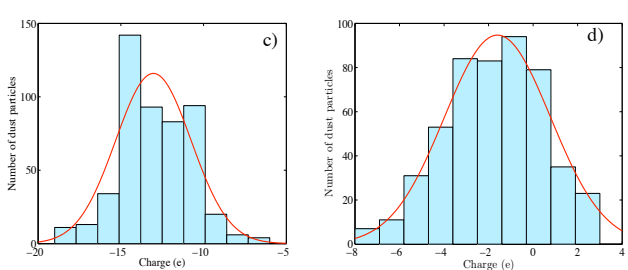
Abrupt transition from ambipolar to free diffusion when $P_{H}=0.5$. c) Slow transition from ambipolar to free diffusion [4]. d) Fast transition from ambipolar to free diffusion [3]

\section{REFERENCES}

1. S. Vladimirov, K. Ostrikov, and A. Samarian, Physics and Applications of Complex Plasmas, Imperial Press, London, 2005.

2. L. Couëdel, M. Mikikian, L. Boufendi, and A. A. Samarian, Phys. Rev. E 74, 026403 (2006).

3. R. J. Freiberg, and L. A. Weaver, Phys. Rev. 170, 336-341 (1968).

4. R. A. Gerber, and J. B. Gerardo, Phys. Rev. A 7, 781-790 (1973).

5. L. Couëdel, A. Samarian, M. Mikikian, and L.Boufendi, Phys. Plasmas -, In press (2008). 